\title{
African Americans' responses to genetic explanations of lung cancer disparities and their willingness to participate in clinical genetics research
}

\author{
Della Brown White, $P h D^{I}$, Laura M. Koehly, $P h D^{I}$, Adedamola Omogbehin, $M D^{2}$, \\ and Colleen M. McBride, PhD
}

\begin{abstract}
Purpose: To assess whether reactions to genetic explanations for disparities in lung cancer incidence among family members of African American patients with lung cancer are associated with willingness to participate in clinical genetics research. Methods: Data are reported for 67 self-identified African Americans aged 18 to 55 years who completed a telephone survey assessing reactions to explanations (i.e., genetics, toxin exposure, menthol cigarettes, and race-related stress) for lung cancer disparities. Majority were female $(70 \%)$, current smokers (57\%), and patients' biological relatives (70\%). Results: Family members rated the four explanations similarly, each as believable, fair, and not too worrisome. Participants also indicated a high level of willingness to participate in genetics research $(M=4.1 \pm 1.0$; scale: $1-5)$. Endorsements of genetics explanations for disparities as believable and fair, and toxin exposure as believable were associated significantly with willingness to participate in genetics research. Conclusion: These results suggest that strategies to encourage African Americans' participation in genetics research would do well to inform potential participants of how their involvement might be used to better understand important environmental factors that affect health disparities. Genet Med 2010:12(8):496-502.
\end{abstract}

Key Words: African Americans, lung cancer disparities, willingness to participate, clinical genetics research, psychosocial factors

M inority participation in genetics research is limited., ${ }^{1,2}$ Efforts to increase minority participation in genetics research have included targeting high-risk populations through cancer registries, cultural tailoring of study materials, addressing issues of trust in the target population, and incorporating flexible intervention and evaluation methods. ${ }^{3}$ However, these methods have shown at best to have only modest improvements in minority participation. ${ }^{4,5}$ Although active recruitment methods (e.g., tumor registries) have been shown to be more effective in increasing minority recruitment than passive accrual approaches (e.g., self-referral), 6,7 it is still unclear why minority participation in genetics research remains low.

It has been widely suggested that African Americans may be apprehensive about participating in genetics research because of

From the ${ }^{1}$ Social and Behavioral Research Branch, National Human Genome Research Institute, National Institutes of Health, Bethesda, Maryland; and ${ }^{2}$ Radiation Oncology, Washington Cancer Institute, Washington Hospital Center, Washington, DC

Della Brown White, PhD, Social and Behavioral Research Branch, National Human Genome Research Institute, National Institutes of Health, NIH, 31 Center Drive, Bldg 31, Room B1B36H, Bethesda, MD 20892-2073. E-mail: whitede@mail.nih.gov

Disclosure: The authors declare no conflict of interest

Submitted for publication December 22, 2009

Accepted for publication April 23, 2010.

Published online ahead of print July 6, 2010.

DOI: 10.1097/GIM.0b013e3181e5e513 a legacy of research abuse in the United States (e.g., Tuskegee syphilis study) and fears that this research will be used as a means to label groups as inferior and foster discrimination..$^{1,8-13}$ Indeed, research has indicated that African Americans who have negative perceptions of genetics research also report less interest in genetics research and testing. ${ }^{14,15}$ However, these suggestions have not always been substantiated by empirical evidence.

There is evidence suggesting that minority groups may be concerned about participating in research linking genes, race/ ethnicity, and health outcomes. ${ }^{8,16,17}$ For example, African Americans have indicated low levels of belief in messages surrounding medications deemed to be effective specifically for African Americans. ${ }^{18}$ African Americans also have reported skepticism about race-based medication information, ${ }^{19}$ fears of a racist conspiracy, ${ }^{18}$ and high levels of suspicion regarding the safety and effectiveness of race-based medications. . $^{17,19,20} \mathrm{New}$ discoveries linking genetic variation to racial differences in health outcomes often termed "disparities"21,22 may elicit similar levels of disbelief and skepticism and emotional responses such as worry or anger that may in turn exacerbate minority groups' negative responses to, and decrease their willingness to participate in, clinical genetics research. ${ }^{16,18,19}$

Indeed, genetic factors are increasingly being examined in an effort to explain racial/ethnic health disparities in common health conditions such as lung cancer. ${ }^{23-27}$ In the United States, there are sizeable disparities in lung cancer incidence and mortality with African Americans disproportionately affected.28,29 Although cigarette smoking is the leading preventable cause of lung cancer, ${ }^{30} \mathrm{racial} / \mathrm{ethnic}$ disparities in lung cancer incidence cannot be explained by differences in smoking behavior alone. . $^{31,32}$ When comparing the smoking patterns of African Americans with whites, we find that historically African Americans begin smoking at older ages and smoke fewer cigarettes per day than whites. ${ }^{29}$ However, African Americans are more likely to be diagnosed with and die from lung cancer than whites..$^{28}$

For this report, we focus on explanations for disparities in lung cancer incidence where conjectures about different causal factors are well described and relatively straightforward to convey to lay audiences. ${ }^{26,27,33}$ Ongoing epidemiologic research suggests that common polymorphisms in a number of genes may increase genetic susceptibility to the harms of environmental exposures such as cigarette smoking and increase risk for diseases such as lung cancer. ${ }^{34,35}$ For example, results of research conducted by Mechanic et al. ${ }^{26}$ suggest that common genetic variations in TP53 may account for increased risk for lung cancer and worsened lung cancer prognosis among African Americans. Also, it has been reported that African Americans may be more likely than whites to carry a less-efficient DNA damage-induced $G_{2}-M$ checkpoint, which may be associated with an increased risk of lung cancer among African Americans. ${ }^{27}$

Other common explanations for disparities in lung cancer incidence include racial differences in menthol cigarette use, 
exposure to toxins, and race-related stress. The majority of African Americans smoke menthol cigarettes (70-80\%), when compared with white smokers $(20-30 \%){ }^{36}$ It has been suggested that menthol numbs the lungs allowing for more smoke to be inhaled with each puff. ${ }^{37}$ Hence, African Americans may smoke fewer cigarettes but take in a greater amount of harmful chemicals. ${ }^{38}$ Furthermore, a greater proportion of African Americans live in poverty than whites $(25 \% \text { vs. } 9 \% \text {, respectively })^{39}$ and may be more likely to live and work near environmental toxins and pollutants than whites. ${ }^{40-42}$ Race-based discrimination has been linked to increased levels of stress and health conditions such as hypertension among African Americans. ${ }^{43-45}$ Accordingly, it could be that increased rates of lung cancer among African Americans may also result from increased smoking behavior in response to prolonged exposure to race-related stress. ${ }^{46}$

The conundrum for clinical genetics research is that adequate minority participation in this research is essential to fully understand the multifactorial influences on lung cancer disparities. Genetic research occurs in a sociopolitical context ${ }^{23,47,48}$ that may influence how minority groups interpret this information and influence their willingness to participate in related research. Moreover, individuals exposed to such information may have preexisting health beliefs and attitudes that lead them to discredit the messages particularly when they do not align with their personal worldviews.

Clinical genetics research generally recruits family members of those affected by cancer. ${ }^{49-51}$ A loved one's diagnosis with lung cancer may influence how an individual responds to explanations for lung cancer disparities. Smoking status may influence these responses such that smokers may perceive explanations for lung cancer disparities differently than nonsmokers. Thus, it is important to consider these factors in evaluating African American's responses to genetic explanations for lung cancer disparities. In this report, we describe an observational study designed to assess reactions to different explanations (i.e., genetics, toxin exposure, menthol cigarettes, and race-related stress) for disparities in lung cancer incidence among family members of African American patients with lung cancer. We also examined whether reactions to these explanations were associated with willingness to participate in clinical genetics research.

\section{MATERIALS AND METHODS}

\section{Eligibility}

Data were collected by structured telephone surveys with self-identified African American patients with lung cancer who were receiving care from Washington Cancer Institute at the Washington Hospital Center and their family members aged $18-55$ years. Patients and family members who self-identified as African American or black and were born in the United States were eligible for the study. We excluded foreign-born blacks because previous research has indicated US-born and foreignborn blacks have different cultural beliefs and health habits, as well as different health outcomes, including cancer. ${ }^{52,53}$ Family members included both biological and nonbiological relatives of the patient and friends considered as family to the patient. To complete the family survey, participants had to meet the criteria for either a current smoker or a never smoker. A current smoker was defined as someone who smoked at least 100 cigarettes in their lifetime and has smoked at least seven in the past 7 days. A never smoker was defined as someone who has not smoked at least 100 cigarettes in their lifetime.

\section{Recruitment and study procedures}

Patients were approached by a recruiter during their clinic visits and asked about whether they were willing to complete a telephone survey about their general well-being and to enumerate family members' smoking status. We elected to have only African American/black recruiters employed by Washington Cancer Institute who already have regular contact with the patient population. Patients who agreed to complete the survey provided written consent to have their personal health information forwarded to the National Human Genome Research Institute.

A trained interviewer contacted patients within 1 week to complete the survey. For patients who were extremely ill, a proxy completed the survey. Only families of patients who provided current mailing addresses and telephone numbers for at least one current smoker were included in the study. These patients were asked for permission to contact all identified smokers and up to two never smokers. To maximize recruitment reach, family members were eligible regardless of their geographic distance from the patient. This necessitated using telephone interviews for data collection.

Family members were mailed an introductory packet that included a letter describing the study purpose, information on how they were identified, and a toll-free telephone number to call to decline participation. Family members who did not call to decline participation were contacted to determine their willingness and eligibility to complete the survey. Call attempts to family members were conducted within a 21-day window, and family members were given options to complete the survey in the evenings and on weekends. Patients and family members who self-identified as current smokers were offered free print smoking cessation materials, and all participants who completed the patient or family survey received a $\$ 35$ gift card. The study procedures were approved by the National Human Genome Research Institute and MedStar Research Institute-Georgetown University Oncology Institutional Review Boards.

\section{Family member survey}

The family member survey took 30-40 minutes to complete and was formatted to ask different questions of smokers and never smokers. All family member surveys were audio taped and administered by trained African American/black telephone interviewers. The primary purpose of the survey was to assess family members' reactions to four common explanations (i.e., genetics, toxin exposure, menthol cigarettes, and race-related stress) for racial/ethnic disparities in lung cancer incidence. To control for order effects associated with using multiple explanations for disparities, family members were administered one of four versions of the survey which varied based on the order in which the explanations were presented.

\section{Measures}

\section{Patient demographics}

Stage of lung cancer diagnosis, age, and gender were obtained from patient medical records. As part of the telephone survey, patients reported race, highest level of education, marital status, current smoking status, and exposure to other household smoking.

\section{Family member demographics}

Family members self-reported their race, age, smoking status, gender, highest level of education, marital status, employment status, exposure to household smoking, and smoking behaviors as part of the telephone survey. Biolog- 
ical relationship to the patient was reported by the patient during the patient survey.

\section{Open-ended explanations for lung cancer disparities}

Before capturing reactions to the four targeted explanations, interviewers read a short narrative to family members describing lung cancer disparities. Participants were asked to provide their opinions, in an open-ended format, about why lung cancer disparities exist. Responses to the narrative were transcribed and evaluated to identify emerging themes, which were used to develop the codebook used for coding participants' responses into close-ended categories. Interrater reliability was calculated for $20 \%$ of the coded material; all items that contained variability reached acceptable reliability (kappa $\geq 0.75$ ). Code frequencies were examined to assess whether other explanations were commonly cited for disparities in lung cancer incidence than the four targeted by the current report.

\section{Reactions to explanations for disparities}

Interviewers read a short narrative to family members that outlined the four targeted explanations for disparities in lung cancer incidence. A description of each narrative is provided in Table 1. After each narrative, family members were asked to rate the level of believability, fairness, and impact of worry for personal lung cancer risk elicited by the explanation. Believability assessed the level of plausibility or credibility of the explanation with participants asked to rate: "On a scale from 1 to 7 where 1 is not at all and 7 is completely believable, how much do you believe the statement that racial differences in lung cancer may be due to blacks having more of the risk versions of some genes than whites?" The fairness item assessed the level of impartiality of the explanation. Participants were asked "On a scale from 1 to 7 where 1 is not at all and 7 is very fair, how fair is the statement?" Worry was assessed by asking participants: "On a scale from 1 to 7 where 1 is not at all and 7 is very worried, how much does the statement make you worry about your own risk for lung cancer?"

\section{Willingness to participate in clinical genetics research}

Willingness to participate in genetics research was assessed with one item. Participants were asked "If you were invited to participate in a clinical research study in which you had to provide a blood sample to identify genetic risk factors for lung cancer, how likely is it that you would participate?" Response categories were 1 = definitely not; 2 = probably not; $3=$ possibly; 4 = probably; and $5=$ definitely would.

\section{Statistical analyses}

We generated descriptive statistics stratified by smoking status to characterize the family members' demographics. Partial correlations were used to evaluate relationships among the reactions to explanations and the main outcome (i.e., willingness to participate in clinical genetics research) while adjusting for smoking status and level of education. The intraclass correlations for the reactions to explanations and willingness to participate in clinical genetics research approximated zero, indicating that family members' responses were essentially independent. Thus, analyses did not control for family clustering. Also, we tested whether the means for reactions to each explanation was different across the four survey versions, and the results indicated no order effects on these variables. Effect sizes were calculated using Cohen's $r$ statistic (small $=0.14$, medium $=0.36$, and large $=0.51) .{ }^{54}$ All statistical analyses were conducted using SAS (Version 9.2; SAS Institute, Cary, NC). A $P$ value of 0.05 was established as a level of significance.

\section{RESULTS}

\section{Patient demographics}

A total of 147 patients were approached for the study of which 93 self-identified African American patients provided written consent to be contacted for the patient survey. A total of 70 patients completed the telephone survey. The majority were female $(64 \%)$ and had been diagnosed with early-stage lung cancer $(64 \%)$. The mean age was $62 \pm 11$ years, $29 \%$ were married, $54 \%$ had a high school education or less, and $11 \%$ reported being current smokers at the time of the screening survey. Only $4 \%$ of patient surveys were completed by a proxy on behalf of the patient. The majority of patients who completed the survey identified at least one family member who smoked $(64 \%), 59 \%$ were eligible to have all identified family members contacted about the study, and $41 \%$ had at least one family member who completed the study.

Table 1 Narratives used to describe each explanation

Explanation Narrative

Genetics

Genes are passed down in families through DNA from one generation to the next. Recently, it has been found that there are versions of genes that make it hard for some people to get rid of harmful chemicals in cigarette smoke. A person who has these risk versions of genes may be more likely to get lung cancer. Some of these gene versions may be more common among blacks than whites. Therefore, racial differences in lung cancer may be due to blacks having more of the risk versions of some genes than whites.

Toxin exposure Being around harmful chemicals in the environment for a long period of time can increase the risk of a person getting lung cancer. Blacks are more likely to live and work in neighborhoods that have more harmful chemicals than whites. Therefore, racial differences in lung cancer may be due to blacks living and working in more harmful environments than whites.

Menthol cigarettes It has been suggested by scientists that menthol numbs the lungs and makes it easier for a smoker to take in more cigarette smoke and harmful chemicals with each puff. Over time, the extra amount of harmful chemicals taken into the body increases the chance of a smoker getting lung cancer. Blacks are more likely to smoke menthol cigarettes than whites. Therefore, racial differences in lung cancer may be due to blacks smoking more menthol cigarettes than whites.

Race-related stress Stress can make it harder for a person's body to fight off disease. People of all different races may experience racism or discrimination; however, blacks are more likely to deal with racism than whites. It may be the case that racial differences in lung cancer may be due to blacks having to deal with more race-related stress than whites. 


\section{Description of family referral}

Patients collectively identified 158 family members. They gave permission to contact 147 of these family members, and 139 family members were successfully referred, i.e., the patient was able to provide complete contact information for the family member. Figure 1 shows the cascade of family referral.

A total of 33 referred family members were ineligible to complete the family survey because of age $(n=25)$ and smoking status $(n=8)$. There were 106 family members deemed eligible to participate, and 67 family members completed the family survey (63\%). The 67 survey completers were from 29 families from which a range of one to six and a median of two family members completed the survey. There were no significant differences in gender, smoking status, or biological relationship between eligible family members who completed the survey and those who did not complete the survey. A description of eligible family who completed the survey and family who did not complete the survey is provided in Table 2 .

\section{Family member characteristics}

The majority of survey completers was female (70\%), 57\% were current cigarette smokers, and $70 \%$ were biologically related to the patient. The mean age was $43 \pm 9.3$ years, $46 \%$ were married, and approximately one third of family members reported exposure to other household smokers. On average, smokers reported smoking 9.2 \pm 5.4 cigarettes in a typical day. The majority smoked their first cigarette within 30 minutes of waking (74\%) and reported smoking menthol cigarettes (89\%).

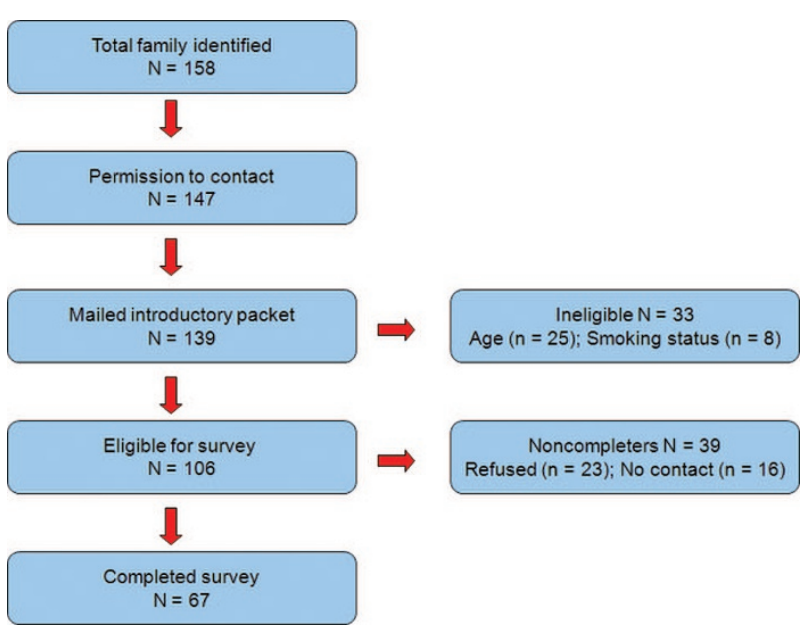

Fig. 1. Cascade of family referrals.

Table 2 Comparison of eligible family members who completed the survey and those who did not complete the survey

\begin{tabular}{lllc}
\hline Characteristics & $\begin{array}{c}\text { Completed } \\
(N=67)\end{array}$ & $\begin{array}{c}\text { Refusal }^{a} \\
(N=23)\end{array}$ & $\begin{array}{c}\text { Not contacted } \\
(N=16)\end{array}$ \\
\hline Biological relative & $70 \%(47)$ & $65 \%(15)$ & $69 \%(11)$ \\
Smoker & $57 \%(38)$ & $70 \%(16)$ & $63 \%(10)$ \\
Female & $70 \%(47)$ & $61 \%(14)$ & $75 \%(12)$ \\
\hline
\end{tabular}

${ }^{a}$ Family member successfully contacted by phone but either verbally refused to complete survey or did not complete the survey within the 21-day call window. ${ }^{b}$ No successful contact of family member within the 21 -day call window.
There was a significant association of smoking status with employment status and education level. Smokers were less likely to be employed full time for pay and reported lower levels of education than never smokers. The sample characteristics of family members by smoking status are shown in Table 3 .

\section{Explanations for disparities}

A total of 60 interviews were included in the analysis of the open-ended data. There were seven recordings excluded due to recording errors. Evaluation of the open-ended data indicated the four targeted explanations were the most frequently mentioned explanations for disparities. The proportion of family members citing one of these explanations ranged from 32 to $15 \%$. There were other less frequently mentioned explanations for disparities. For example, $12 \%$ of participants cited racial/ ethnic differences in attention to self-care and $8 \%$ indicated differences in lifestyle factors as explanations for lung cancer disparities

\section{Reactions to explanations for disparities}

Overall, family members endorsed explanations of racial differences in genetic risk, toxin exposure, menthol cigarette use, and race-related stress as believable and fair but not particularly worrisome (Table 4). Although toxin exposure was endorsed as the most believable explanation for lung cancer disparities (mean $=5.6 \pm 1.6$; scale: $1=$ not at all and $7=$

Table 3 Family member characteristics by smoking status

\begin{tabular}{|c|c|c|c|c|}
\hline Characteristics & $\begin{array}{c}\text { Total } \\
(N=67)^{a}\end{array}$ & $\begin{array}{l}\text { Smokers } \\
(N=38)\end{array}$ & $\begin{array}{c}\text { Never } \\
\text { smokers } \\
(N=29)\end{array}$ & $P$ \\
\hline Mean age (yr) (SD) & $43(9.3)$ & $44(8.5)$ & $41(10.2)$ & 0.15 \\
\hline Female & $70 \%(47)$ & $68 \%(26)$ & $72 \%(21)$ & 0.72 \\
\hline Married & $46 \%(31)$ & $37 \%(14)$ & $59 \%(17)$ & 0.13 \\
\hline Employed & $64 \%(43)$ & $53 \%(20)$ & $79 \%(23)$ & $0.03^{b}$ \\
\hline \multicolumn{5}{|l|}{ Education } \\
\hline High school or less & $31 \%(21)$ & $42 \%(16)$ & $17 \%(5)$ & $0.03^{b}$ \\
\hline $\begin{array}{l}\text { Some college/ } \\
\text { technical }\end{array}$ & $49 \%(33)$ & $47 \%(18)$ & $52 \%(15)$ & \\
\hline $\begin{array}{l}\text { College degree or } \\
\text { higher }\end{array}$ & $19 \%(13)$ & $10 \%(4)$ & $31 \%(9)$ & \\
\hline $\begin{array}{l}\text { Household smokers } \\
\text { (other than } \\
\text { respondent) }\end{array}$ & $30 \%(20)$ & $32 \%(12)$ & $28 \%(8)$ & 0.57 \\
\hline Biological relative & $70 \%(47)$ & $63 \%(24)$ & $79 \%(23)$ & 0.15 \\
\hline \multicolumn{5}{|l|}{ Smoking behavior } \\
\hline $\begin{array}{l}\text { Mean number of } \\
\text { cigarettes smoked } \\
\text { in a typical } \\
\text { day (SD) }\end{array}$ & - & $9.2(5.4)$ & 一 & - \\
\hline $\begin{array}{l}\text { First cigarette within } \\
30 \text { min of waking }\end{array}$ & - & $74 \%(28)$ & - & - \\
\hline Menthol cigarette use & - & $89 \%(34)$ & - & - \\
\hline
\end{tabular}


Table 4 Reactions to explanations and partial correlations between willingness to participate in clinical genetics research and reactions, controlling for education level and smoking status $(N=67)^{a}$

\begin{tabular}{|c|c|c|}
\hline Characteristics $^{b}$ & Mean (SD) & $r$ \\
\hline \multicolumn{3}{|l|}{ Genetics } \\
\hline Believe & $5.2(1.5)$ & $0.26^{c}$ \\
\hline Fair & $5.3(1.6)$ & $0.36^{d}$ \\
\hline Worry & $4.4(2.1)$ & 0.21 \\
\hline \multicolumn{3}{|l|}{ Toxin exposure } \\
\hline Believe & $5.6(1.6)$ & $0.25^{c}$ \\
\hline Fair & $5.3(2.0)$ & 0.16 \\
\hline Worry & $4.2(2.3)$ & 0.20 \\
\hline \multicolumn{3}{|c|}{ Menthol cigarettes } \\
\hline Believe & $5.3(1.7)$ & 0.20 \\
\hline Fair & $5.1(1.9)$ & 0.14 \\
\hline Worry & $4.0(2.5)$ & $0.24^{e}$ \\
\hline \multicolumn{3}{|c|}{ Race-related stress } \\
\hline Believe & $5.1(1.9)$ & 0.11 \\
\hline Fair & $5.0(2.1)$ & 0.03 \\
\hline Worry & $3.7(2.2)$ & 0.18 \\
\hline \multicolumn{3}{|c|}{$\begin{array}{l}{ }^{a_{n}} \text { missing on some items. } \\
{ }^{0} \text { On scale from } 1 \text { to } 7: 1=\text { not at all believable/fair/worried and } 7=\text { completely } \\
\text { believe/very fair/very worried. } \\
{ }^{C} P<0.05 \text {. } \\
{ }^{P} P<0.01 \\
{ }^{P} P<0.10\end{array}$} \\
\hline
\end{tabular}

completely believable), reactions to genetics as an explanation were relatively favorable, such that the mean scores for believability and fairness were $5.2 \pm 1.5$ and $5.3 \pm 1.6$, respectively. Race-related stress was endorsed as the least believable, fair, and worrisome explanation (means $=5.1 \pm 1.9 ; 5.0 \pm 2.1$; and $3.7 \pm 2.2$, respectively). Nonetheless, there were no significant differences in evaluations across the four explanations.

\section{Willingness to participate in clinical genetics research}

Family members indicated a high level of willingness to participate in clinical genetics research (mean $=4.1 \pm 1.0$; scale: $1=$ definitely not and $5=$ definitely would). Partial correlations between willingness to participate in clinical genetics research and reactions to the four explanations while controlling for smoking status and education level are presented in Table 3. Endorsements of genetics as a believable and fair explanation were positively associated with willingness to participate in genetics research. Also, endorsements of toxin exposure as a believable explanation were positively associated with willingness to participate. Worry about menthol use as an explanation tended to be positively associated with willingness to participate; however, this association was not statistically significant. None of the reactions to race-related stress as an explanation for racial differences in lung cancer was significantly associated with willingness to participate.

\section{DISCUSSION}

To our knowledge, this is the first empirical report to assess African Americans' responses to genetic explanations for racial/ ethnic health disparities. Our sample of African American relatives of patients with lung cancer did not respond negatively to explanations conjuring racial/ethnic differences in genetic variation to explain lung cancer disparities. Reactions to genetic explanations were similar to reactions to the other common explanations. Additionally, favorable endorsements of genetic explanations as a believable and fair explanation were significantly associated with willingness to participate in genetics research.

Previous research has indicated that minorities have negative perceptions about the use of race-based medicine. ${ }^{8,16-20}$ However, our results suggest that genetics as a basis for racial/ethnic health disparities need not limit minority participation in genetics research. The ever increasing media coverage describing anticipated health benefits of genetic discovery may be increasing African American's receptivity to messages linking genes, race, and health. ${ }^{55,56}$ However, it is important to note that the genetics explanation we used focused on racial/ethnic differences in susceptibility to the harmful effects of smoking. It may be the case that messages that consider the role of gene-environment interactions in health disparities instead of geneticsonly messages may be more acceptable to minority populations and may buffer against skepticism about the use of genetics research to foster discrimination.

Although none of the explanations for lung cancer disparities elicited a particularly strong emotional reaction in terms of high worry about personal lung cancer risk, participants rated genetic explanations as having the highest impact on lung cancer worry. This is not surprising because $70 \%$ of family members who completed the survey were biologically related to the patient. Previous research has shown African American women with a family history of breast or ovarian cancer to be less likely to participate in BRCA1/2 genetic services compared with similar white women. ${ }^{57}$ However, in this study, the level of worry generated by genetics as an explanation for disparities did not significantly inhibit willingness to participate in genetics research. This suggests that reactions to genetic explanations and willingness to participate in genetic research may differ for different health conditions.

Limitations of the study must be considered in interpreting these results. The data reported are cross-sectional, and thus no causative inferences can be made. There was a relatively small sample. Sixty-three percent of eligible family members completed the survey. This response rate is somewhat lower than other studies involving survey only methodology. ${ }^{15,58}$ However, minority participation in research requiring more commitment such as genetic testing and participation in cancer genetics registry has been much lower. ${ }^{2,6,59}$ In this report, willingness to participate in research was based on a hypothetical scenario and may not accurately reflect how participants would respond to an actual invitation to research. Indeed, previous research has indicated that minorities express high levels of willingness to participate in genetics research, but actual participation remains limited among minorities when invited to participate. . $^{2,659,60}$

Furthermore, these families were dealing with the diagnosis of lung cancer; therefore, results may not be generalizable to African Americans without personal experiences of lung cancer, suggesting the need for replication in larger and more diverse samples of African Americans and in nonclinical settings. Our small sample did not enable us to control analyses for patient characteristics (e.g., stage of lung cancer, age, and smoking history) in examining associations of reactions to explanations 
with willingness to participate in genetics research. Future studies with larger samples are needed to examine the role of such factors in family members' beliefs about lung cancer. Also, we had limited demographic information (i.e., gender, smoking status, and relationship to patient) on family members who did not complete the survey. Factors such as education level are commonly found to be negatively associated with research participation. ${ }^{5}$

As part of this research, we addressed four common explanations for disparities in lung cancer incidence. The narratives and questions used to assess reactions were developed as part of the study protocol. We aimed to provide scientific evidence for each explanation while at the same time not biasing respondents by presenting either explanation as more plausible than the others. However, variability in certainty associated with each explanation may have influenced family members' responses. These items need to be evaluated for reliability and validity for future use. Furthermore, although results of our open-ended survey indicated our four targeted explanations as the most commonly cited, there may be additional explanations and reactions that African Americans consider important in understanding lung cancer disparities, which might be associated with willingness to participate in genetics research. These might have been elicited had we used focus groups or face-to-face interviews rather than telephone surveys.

In the future, it is important to examine the influences of other factors such as smoking status, causal attributions for lung cancer, and experiences with discrimination on beliefs about the role of these factors in disparities and willingness to participate in genetics research. Also, additional work is needed to examine cognitive and emotional reactions to genetic explanations for disparities in health outcomes that do not have a well established and highly stigmatizing behavioral risk factor such as cigarette smoking but for which disparities are increasingly being attributed to genetics (e.g., breast cancer and asthma).

This research is a first step in gaining information about how African American smokers and never smokers personally affected by lung cancer might respond to clinical genetics research related to health disparities in lung cancer. To fully understand the role of genetics and other environmental factors in lung cancer disparities, more minority participation is needed. The results of this report suggest that developing messages that inform participants how their involvement in genetics research might be used to better understand the impact of other environmental factors on lung cancer disparities may generate more willingness to participate in genetics research.

\section{ACKNOWLEDGMENTS}

This work was supported by the Intramural Research Program of the National Human Genome Research Institute, National Institutes of Health.

The authors thank Lorraine Denis-Cooper, Studly Auguste, Shea Lott, and ShaDonna Jackson for their assistance with recruitment and data collection. The authors also thank all the patients and their family who participated in this study.

\section{REFERENCES}

1. Sterling R, Henderson GE, Corbie-Smith G. Public willingness to participate in and public opinions about genetic variation research: a review of the literature. Am J Public Health 2006;96:1971-1978.

2. Moorman PG, Skinner CS, Evans JP, et al. Racial differences in enrolment in a cancer genetics registry. Cancer Epidemiol Biomarkers Prev 2004;13: $1349-1354$

3. James RD, Yu JH, Henrikson NB, Bowen DJ, Fullerton SM. Health Disparities Working Group. Strategies and stakeholders: minority recruitment in cancer genetics research. Community Genet 2008;11:241-249.
4. Ramirez AG, Miller AR, Gallion K, San Miguel De Majors S, Chalela P, García Arámburo S. Testing three different cancer genetics registry recruitment methods with Hispanic cancer patients and their family members previously registered in local cancer registries in Texas. Community Genet 2008;11:215-223.

5. Skinner CS, Schildkraut JM, Calingaert B, et al. Factors associated with African Americans' enrollment in a national cancer genetics registry. Community Genet 2008;11:224-233.

6. Hughes C, Peterson S, Ramirez A, et al. Minority recruitment in hereditary breast cancer research. Cancer Epidemiol Biomarkers Prev 2004; 13:1146-1155.

7. Patterson AR, Davis H, Shelby K, et al. Successful strategies for increasing African American participation in cancer genetic studies: hopeful signs for equalizing the benefits of genetic medicine. Community Genet 2008; $11: 208-214$

8. Bates BR, Lynch JA, Bevan JL, Condit CM. Warranted concerns, warranted outlooks: a focus group study of public understandings of genetic research. Soc Sci Med 2005;60:331-344.

9. Schulz A, Caldwell C, Foster S. "What are they going to do with the information?" Latino/Latina and African American perspectives on the Human Genome Project. Health Educ Behav 2003;30:151-169.

10. Peters N, Rose A, Armstrong K. The association between race and attitudes about predictive genetic testing. Cancer Epidemiol Biomarkers Prev 2004; 13:361-365.

11. Thompson H, Valdimarsdottir H, Jandorf L, Redd W. Perceived disadvantages and concerns about abuses of genetic testing for cancer risk: differences across African American, Latina and Caucasian women. Patient Educ Couns 2003;51:217-227.

12. Laskey S, Williams J, Pierre-Louis J, O'Riordan M, Matthews A, Robin NH. Attitudes of African American premedical students toward genetic testing and screening. Genet Med 2003;5:49-54.

13. Bussey-Jones J, Henderson G, Garrett J, Moloney M, Blumenthal C, Corbie-Smith G. Asking the right questions: views on genetic variation research among black and white research participants. J Gen Intern Med 2009;24:299-304.

14. Thompson HS, Valdimarsdottir HB, Duteau-Buck C, et al. Psychosocial predictors of BRCA counseling and testing decisions among urban AfricanAmerican women. Cancer Epidemiol Biomarkers Prev 2002;11:1579-1585.

15. Halbert $\mathrm{CH}$, Gandy $\mathrm{OH} \mathrm{Jr}$, Collier A, Shaker L. Intentions to participate in genetics research among African American smokers. Cancer Epidemiol Biomarkers Prev 2006;15:150-153.

16. Condit C, Bates B. How lay people respond to messages about genetics, health, and race. Clin Genet 2005;68:97-105.

17. Bevan JL, Lynch JA, Dubriwny TN, et al. Informed lay preferences for delivery of racially varied pharmacogenomics. Genet Med 2003;5:393-399.

18. Bates BR, Poirot K, Harris TM, Condit CM, Achter PJ. Evaluating directto-consumer marketing of race-based pharmacogenomics: a focus group study of public understandings of applied genomic medication. $J$ Health Commun 2004;9:541-559.

19. Condit C, Templeton A, Bates BR, Bevan JL, Harris TM. Attitudinal barriers to delivery of race-targeted pharmacogenomics among informed lay persons. Genet Med 2003;5:385-392.

20. DeMarco M. Views on personalized medicine: do the attitudes of African American and White prescription drug consumers differ? [published online ahead of print September 23, 2009] Public Health Genomics doi: 10.1159/ 000242199.

21. Carter-Pokras O, Baquet C. What is a "health disparity"? Public Health Rep 2002;117:426-434.

22. Krieger N. A glossary for social epidemiology. J Epidemiol Community Health 2001;55:693-700.

23. Braun L. Race, ethnicity, and health: can genetics explain disparities? Perspect Biol Med 2002;45:159-174.

24. Abidoye O, Ferguson MK, Salgia R. Lung carcinoma in African Americans. Nat Clin Pract Oncol 2007;4:118-129.

25. Flenaugh EL, Henriques-Forsythe MN. Lung cancer disparities in African Americans: health versus health care. Clin Chest Med 2006;27:431-439.

26. Mechanic LE, Bowman ED, Welsh JA, et al. Common genetic variation in TP53 is associated with lung cancer risk and prognosis in African Americans and somatic mutations in lung tumors. Cancer Epidemiol Biomarkers Prev 2007; $16: 214-222$.

27. Zheng YL, Loffredo CA, Alberg AJ, et al. Less efficient g2-m checkpoint is associated with an increased risk of lung cancer in African Americans. Cancer Res 2005;65:9566-9573.

28. Horner MJ, Ries LAG, Krapcho M, et al. SEER cancer statistics review, 1975-2006. Bethesda, MD: National Cancer Institute, 2009. Available at: http://seer.cancer.gov/csr/1975_2006/. Based on November 2008 SEER data submission, posted to the SEER web site. Accessed June 11, 2009.

29. US Department of Health and Human Services. Tobacco use among US racial/ethnic minority groups-African Americans, American Indians and Alaska Natives, Asian Americans and Pacific Islanders, and Hispanics: a report of the surgeon general. Atlanta, GA: US Department of Health and 
Human Services, Centers for Disease Control and Prevention, National Center for Chronic Disease Prevention and Health Promotion, Office on Smoking and Health, 1998.

30. Alberg AJ, Brock MV, Samet JM. Epidemiology of lung cancer: looking to the future. J Clin Oncol 2005;23:3175-3185.

31. Pinsky P. Racial and ethnic differences in lung cancer incidence: how much is explained by differences in smoking patterns? (United States). Cancer Causes Control 2006;17:1017-1024.

32. Alberg A, Nonemaker J. Who is at high risk for lung cancer? Population-level and individual-level perspectives. Semin Respir Crit Care Med 2008;29:223232.

33. Haiman CA, Stram DO, Wilkens LR, et al. Ethnic and racial differences in the smoking-related risk of lung cancer. N Engl J Med 2006;354:333-342.

34. Thier R, Brüning T, Roos P, et al. Markers of genetic susceptibility in human environmental hygiene and toxicology: the role of selected CYP, NAT and GST genes. Int J Hyg Environ Health 2003;206:149-171.

35. Liu G, Zhou W, Christiani D. Molecular epidemiology of non-small cell lung cancer. Semin Respir Crit Care Med 2005;26:265-272.

36. Giovino GA, Sidney S, Gfroerer JC, et al. Epidemiology of menthol cigarette use. Nicotine Tob Res 2004;6(suppl 1):S67-S81.

37. Ahijevych K, Garrett BE. Menthol pharmacology and its potential impact on cigarette smoking behavior. Nicotine Tob Res 2004;6(suppl 1):S17-S28.

38. Garten S, Falkner RV. Role of mentholated cigarettes in increased nicotine dependence and greater risk of tobacco-attributable disease. Prev Med 2004; 38:793-798.

39. DeNavas-Walt C, Proctor BD, Smith JC. Income, poverty, and health insurance coverage in the United States: 2008. Washington, DC: U.S. Government Printing Office, 2009.

40. Birdsey J, Alterman T, Petersen M. Race, occupation, and lung cancer: detecting disparities with death certificate data. J Occup Environ Med 2007;49:1257-1263

41. Gadgeel SM, Kalemkerian GP. Racial differences in lung cancer. Cancer Metastasis Rev 2003;22:39-46.

42. Stuart AL, Mudhasakul S, Sriwatanapongse W. The social distribution of neighborhood-scale air pollution and monitoring protection. J Air Waste Manag Assoc 2009;59:591-602.

43. Clark R, Anderson NB, Clark VR, Williams DR. Racism as a stressor for African Americans. A biopsychosocial model. Am Psychol 1999;54:805-816.

44. Williams DR, Mohammed SA. Discrimination and racial disparities in health: evidence and needed research. J Behav Med 2009;32:20-47.

45. Wyatt S, Williams D, Calvin R, Henderson F, Walker E, Winters K. Racism and cardiovascular disease in African Americans. Am J Med Sci 2003;325: 315-331.

46. Colby JP Jr, Linsky AS, Straus MA. Social stress and state-to-state differ- ences in smoking and smoking related mortality in the United States. Soc Sci Med 1994;38:373-381.

47. Caulfield T, Harry S. Popular representations of race: the news coverage of BiDil. J Law Med Ethics 2008;36:485-490.

48. Shields AE, Fortun M, Hammonds EM, et al. The use of race variables in genetic studies of complex traits and the goal of reducing health disparities: a transdisciplinary perspective. Am Psychol 2005;60:77-103.

49. Ersig AL, Williams JK, Hadley DW, Koehly LM. Communication, encouragement, and cancer screening in families with and without mutations for hereditary nonpolyposis colorectal cancer: a pilot study. Genet Med 2009; 11:728-734

50. Koehly LM, Peterson SK, Watts B, Kempf KK, Vernon SW, Gritz ER. A social network analysis of communication about hereditary nonpolyposis colorectal cancer genetic testing and family functioning. Cancer Epidemiol Biomarkers Prev 2003;12:304-313.

51. O'Neill SC, White DB, Sanderson SC, et al. The feasibility of online genetic testing for lung cancer susceptibility: uptake of a web-based protocol and decision outcomes. Genet Med 2008;10:121-130.

52. Arthur CM, Katkin ES. Making a case for the examination of ethnicity of Blacks in United States Health Research. J Health Care Poor Underserved 2006; 17:25-36.

53. Lucas JW, Barr-Anderson DJ, Kington RS. Health status, health insurance, and health hare utilization patterns of immigrant Black men. Am J Public Health 2003;93:1740-1747.

54. Cohen J. Statistical power analysis for the behavioral sciences, 2nd ed. Hillsdale, NJ: Erlbaum, 1988.

55. Collins FS, Green ED, Guttmacher AE, Guyer MS. US National Human Genome Research Institute. A vision for the future of genomics research. Nature 2003;422:835-847.

56. Ginsburg GS, Willard HF. Genomic and personalized medicine: foundations and applications. Transl Res 2009;154:277-287.

57. Armstrong K, Micco E, Carney A, Stopfer J, Putt M. Racial differences in the use of BRCA $1 / 2$ testing among women with a family history of breast or ovarian cancer. JAMA 2005;293:1729-1736.

58. McBride CM, Lipkus I, Jolly D, Lyna P. Interest in testing for genetic susceptibility to lung cancer among Black college students "at risk" of becoming cigarette smokers. Cancer Epidemiol Biomarkers Prev 2005;14: 2978-2981.

59. Halbert CH, Kessler L, Stopfer JE, Domchek S, Wileyto EP. Low rates of acceptance of BRCA1 and BRCA2 test results among African American women at increased risk for hereditary breast-ovarian cancer. Genet Med 2006;8:576-582

60. Olsen SJ, Malvern KT, May BJ, Jenkins IL, Griffin CA. Partnership with an African American sorority to enhance participation in cancer genetics research. Community Genet 2008;11:201-207. 